\title{
Autotraducción literaria desde el vasco ${ }^{1}$
}

\author{
Karlos Cid ABAsolo \\ Universidad Complutense de Madrid \\ abasolo@filol.ucm.es
}

\section{RESUMEN}

El hecho de que muchos autores en lengua vasca sean bilingües (es decir, que dominen tanto el vascuence como la respectiva lengua en contacto, a saber, el español o el francés) anima a muchos de ellos a encargarse de la traducción de sus obras a dichas lenguas. Ello acarrea dos consecuencias importantes: que más que de autotraducciones haya que hablar de autoversiones (el autor, como autor que es, se permite la licencia de introducir numerosas modificaciones en el texto español o francés respecto del original), y que algunos escritores (Bernardo Atxaga, por ejemplo) prefieran que las traducciones a terceras lenguas partan, no del original en vasco, sino de dichas autotraducciones. En este artículo trataremos de analizar ambos hechos, que suelen estar interrelacionados.

Palabras clave: Comparatismo ibérico, traducción literaria, autotraducción, lengua puente, literaturas en contacto.

\section{Literary Self-Translation from Basque}

\begin{abstract}
The fact that many Basque authors are bilingual (i.e., they dominate both Basque and Spanish or French) encourages many of them to translate their works into such languages in contact. This has two important consequences: on the one hand, rather than about self-translations we have to talk about selfversions (the author can afford to introduce a lot of modifications in the Spanish or French text), and, on the other hand, some authors (like Bernardo Atxaga) prefer translations into third languages to be done, not from the original Basque text, but from the aforementioned self-translations. This article will attempt to reveal the possible causes of both facts.
\end{abstract}

Keywords: Iberian comparative studies, literary translation, self-translation, bridge-language, literatures in contact.

${ }^{1}$ Quiero expresar mi agradecimiento a Arantzazu Royo por haberme dado noticia de fuentes bibliográficas que me han sido de gran utilidad en el momento de elaborar esta colaboración. 
Toda autotraducción tiene algo de autopsia en vivo. El peligro no es que entres en crisis con la traducción, sino con el original.

(Harkaitz Cano)

Uno, al traducirse, hace todas las trampas que quiera.

\section{Introducción ${ }^{2}$}

(Felipe Juaristi)

La lengua y la literatura vascas, con el apoyo de amplios sectores sociales y ciertos poderes públicos, gozan hoy de un prestigio que les permite ser equiparables a otras lenguas y literaturas. A día de hoy, y según el barómetro Calvet, el vascuence ocupa el puesto 51 entre las lenguas del mundo. Ello, como es lógico, ha tenido una consecuencia directa en el mundo de la traducción: verter literatura vasca a otros idiomas es hoy un fenómeno normal -hay traducciones a más de treinta y cinco lenguas $^{3}$-. Precisamente el número de libros traducidos «desde» y «a» tal o cual lengua es uno de los parámetros por los que se rige dicho barómetro.

No obstante, hace apenas treinta años, la situación era bien distinta. Aquello lo vivió en carne propia Arantxa Urretabizkaia (San Sebastián, 1947):

Tengo que decir que en todos esos años la producción literaria en euskera no solía ser traducida. Había, como mucho, antologías poéticas o libros de cuentos traducidos y publicados a diversas lenguas minorizadas. Pero ni nosotros buscábamos ser traducidos al castellano o al francés, ni a las grandes o medianas editoriales se les pasaba por la cabeza que pudiera haber algo de interés en la literatura escrita en euskera. (Urretabizkaia 2011)

La traducción de la literatura vasca a otros idiomas revela, a juicio de E. Manterola (2012b: 128), la realidad diglósica que vive el País Vasco: casi la mitad del total de traducciones se realiza al español (muchas de ellas mediante autotraducción), y en muchas ocasiones se traduce a otras lenguas, no desde el texto original, sino desde la traducción al español ${ }^{4}$. Iban Zaldua (San Sebastián, 1966) ironiza respecto a ambos aspectos.

Esto, por no hablar de la práctica de la autotraducción, bastante extendida y que para algunos es un signo evidente del subdesarrollo de nuestra lengua -los que protestan, por lo general y seguramente no por casualidad, suelen ser traductores: hay que

\footnotetext{
${ }^{2}$ Pensando en el lector poco familiarizado con la literatura vasca y dado el corpus poligenético al que se remite, tras los títulos de las obras se hace referencia al género al que pertenecen. Las iniciales empleadas tras la fecha de publicación son: $\mathrm{P}$ [poesía], $\mathrm{N}$ [narrativa].

3 Vid. UPV/EHU (s.a.), EIZIE (s.a.), Manterola (2007, 2012a, 2012b), Olaziregi (2000, 2001) y, sobre literatura infantil, López Gaseni (2007).

${ }^{4}$ J. M. López Gaseni (2005) incide en esos dos puntos como un déficit de la literatura vasca. Por otro lado, la autotraducción es el punto de arranque de un breve relato de Iban Zaldua titulado Itzulpe$n a$ ('Traducción'), incluido, en español, en su ensayo de 2012 Ese idioma raro y poderoso. Once decisiones cruciales que un escritor vasco está obligado a tomar.
} 
defender el oficio de los intrusos, aunque estos sean los propios autores-. De todas maneras, hay que señalar que la formación de un grupo cada vez más numeroso de traductores, sobre todo al español, pero también a otras lenguas, ha avanzado mucho en estos últimos años: la autotraducción ya no es tan inevitable como en otras épocas. Anteriormente, la prioridad había sido formar traductores al euskera, mucho más que traductores desde el euskera. (Zaldua 2012: 21)

Pese a que la situación oficial del vascuence sea algo mejor por estos lares, a la hora de ser traducido la opción de «puentear» al español sigue siendo, seguramente, la más celebrada por parte de los vasquistas de pro, sobre todo por aquellos que profesan un nacionalismo más o menos acentuado. A fin de cuentas, no pasar por el castellano es una manera de desligarse del vínculo «colonial», una expresión de autonomía cultural y política. (Zaldua 2012: 106-107)

En cambio, Joseba Sarrionandia (Yurreta, Vizcaya, 1958), apuntando en la línea de E. Manterola y J. M. López Gaseni, sí ve en la autotraducción una deficiencia.

Behialako euskal liburuek axolagabezia orokorraren abantaila zuten, Leilako ahuntzek bezala. Errekonozimendu publikoarekin ere, euskal idazleei ez zaie ahuntz marka hori kentzen. Espainian gaztelerazko idazlea aurkezten denean «idazle» da, euskarazko idazlea «euskarazko» da, ahuntz airearekin. Marka hori ezabatzeko, aparteko galanteo intelektual, ideologiko eta protokolozkoak egin behar izango ditu, Espainian behintzat, Munduko Literaturaren enuntziazio lekuetara heltzeko. Gainera, gazteleratu egin behar izango du, eta benetako itzulpena egin nahi badu, berak egin beharko du. «Idazle» moduan besteak baino gutxiago ez dela frogatzeko. Hala, gaztelerazko idazle bihurtuko da bide batez..$^{5}$ (Sarrionandia 2010: 535)

\section{La autotraducción}

La autotraducción en la literatura vasca está limitada, como es lógico, a las lenguas de contacto con el vascuence: el español y el francés. Los autores éuscaros de la zona española tienen un bilingüismo vasco-español, y los de la zona francesa (mucho menos numerosos) uno vasco-francés. Así pues, las autotraducciones suelen ser al español o al francés. En las traducciones al español, la autotraducción representa un porcentaje nada desdeñable: más de la tercera parte. Ejemplo de autotraducción al francés es Septentrio $(2007$, N), de Aurelia Arkotxa (Baigorri, País Vasco

5 «Antaño, los libros vascos, al igual que las cabras de Leila, contaban con la ventaja de la indiferencia. Incluso contando con el reconocimiento público, los escritores vascos no se libran de esa marca de cabra. Cuando en España es presentado un escritor en castellano, es "escritor" a secas; en cambio, el escritor en vasco es "escritor en vasco", con aire de cabra. Para borrar esa marca tendrá que hacer unos extraordinarios galanteos intelectuales, ideológicos y protocolarios, al menos en España, para llegar a los lugares de enunciación de la Literatura Mundial. Además, tendrá que ser traducido al castellano, y si quiere hacer una verdadera traducción, tendrá que hacerla él mismo, para demostrar que, como "escritor", no es menos que los demás. Así, y de paso, se convertirá en escritor en castellano». (La traducción es nuestra. Este fragmento del original no aparece en la versión castellana). 
Francés, 1953), cuya versión original vasca fue publicada en 2001. Es rara la autotraducción a otros idiomas.

Varios pueden ser los motivos que impulsen a un escritor vasco a autotraducirse: el hecho de que sea, stricto sensu, escritor bilingüe, es decir, que publique tanto en vascuence como en español o francés (tal es el caso, por ejemplo, de Iban Zaldua); el deseo de controlar, como creador, su texto (más aún si se trata de poesía); los ingresos que puede reportarle realizar la traducción; la circunstancia contraria, es decir, la falta de recursos económicos para contratar a un traductor profesional; la premura de tiempo (por ejemplo, cuando se trata de presentar una candidatura al Premio Nacional de Literatura); el que haya transcurrido poco tiempo entre la publicación del original y la traducción (por el contrario, si han pasado varios años, el autor puede sentir quizás cierta desafección respecto de aquella obra escrita en unas circunstancias concretas de su vida), razón aludida por Juan Luis Zabala (Azcoitia, 1963):

Beti esaten da liburua, argitaratu ondoren, ume bat bezala dela, emantzipatu eta independizatu egiten dela. Bada, nik uste dut idazleak ez duela bueltatu nahi argitaratu den liburura, eta askotan, gainera, zenbat eta denbora gehiago pasatu, okerrago. Berez, autoitzulpenaren egoera egoki bakarra argitaratu aurrekoa da. Hori planteatzen zuen Atxagak Gizona bere bakardadean liburuarekin, ez? Uste dut esaten zuela horrela lan egiteko asmoa zuela, hau da, euskaraz idatzi ahala itzultzea, eta gainera horrek laguntzen ziola euskarazkoan pixka bat hutsalak ziren edo funtzionatzen ez zuten pasarteak konpontzen. Horrela eginda, autoitzulpenak zentzua izan dezake, baina bestela, nire ustez, ez. Liburua argitaratuta ikusten duzun lehen aldian, ez da minutu bat pasatzen lehenengo akatsa ikusi baino lehen. Eta hortik hasita, jada, gaizki pasatzen duzu... Orduan, oso mentalizazio handia beharko nuke nik horretara bueltatzeko eta liburu horrekin orduak pasatzeko. ${ }^{6}$ (Montorio 2007: 72)

Por su parte, Bernardo Atxaga (Asteasu, Guipúzcoa, 1951), en su página web (vid. Atxaga 2004), añade la genealogía lingüística (la naturaleza no indoeuropea del vascuence) a los argumentos favorables a la autotraducción.

Como sabe, el euskera es una lengua preindoeuropea, anterior al latín, y, por muy mezclada que esté con el propio latín y otras lenguas, resulta una lengua bastante extraña. Es mejor que el salto de una a otra lo haga el propio escritor. De lo contrario corre el riesgo de encontrarse con un texto que no le suena nada, que le resulta ajeno.

${ }^{6}$ «Siempre se dice que el libro, tras ser publicado, es como un hijo, que se emancipa y se independiza. Pues yo creo que el escritor no quiere volver al libro que se ha publicado, y muchas veces, además, cuanto más tiempo transcurra, peor. De por sí, la única situación idónea de la autotraducción es la previa a la publicación. Eso es lo que planteaba Atxaga con el libro Gizona bere bakardadean [El hombre solo], ¿no? Creo que decía que tenía intención de trabajar del siguiente modo: traduciendo al castellano a medida que escribía en vasco, y que además eso le ayudaba a resolver pasajes que en el texto en vascuence eran un poco insustanciales o no funcionaban. Haciéndolo así, la autotraducción puede tener sentido, pero, de lo contrario, creo que no. La primera vez que ves publicado tu libro, no pasa ni un minuto antes de que veas la primera errata. Y lo pasas fatal... Así que, necesitaría una gran mentalización para volver a ello y pasar horas y horas con ese libro». (La traducción es nuestra). 
Por el contrario, muy diversas son las razones que pueden llevar a un autor vasco a no autotraducirse. Las siguientes nos las aportan, respectivamente, Anjel Lertxundi (Orio, Guipúzcoa, 1948) en las dos primeras citas, y Jon Alonso (Pamplona, 1958) en la tercera.

Ipuin bat bada antologietan dabilena, nik neuk gaztelaniara itzulitakoa: Lur hotz hau ez da Santo Domingo izeneko ipuina. Ipuin hori itzuli nuenean, hasieran ez nintzen konturatu, eta gero, prozesua bukatu ondoren, berriz, jabetu nintzen arazo izugarriaz, nik neuk testuarekin izan nuen arazo izugarriaz. Aitorpen bat egin beharra daukat: euskaraz argitaratua dagoen testua eta gaztelaniaz dagoena desberdinak dira. Gaztelaniazkoak, esango nuke plus bat duela. Nolabait, halako working progress bat eginaz, halako tranpatxoak eginaz, testu originalean dauden ahuleziak saihestuz, beste modu batera bideratuz, eta abar, jatorrizko testua traizionatu egin nuen. Zilegi nuen, neurea zen, eta sortzen ari nintzen berria ere neurea zen, baina, jakina, itzulpen gisa agertzen zen eta ez egokitzapen edo moldapen gisa. Alde horretatik ipuin hura itzuli, gero argitaratu eta handik denbora puska batera kontrastatu nituenean bi testuak, halako erabaki bat hartu nuen: nik ezin nuela neure buruaren itzultzaile izan. ${ }^{7}$ (Egia 1999: 113-114)

Zergatik esaten dut orduan nik ezin dudala nire buruaren itzultzaile izan, gazteleraz ere idazten dudalarik, behintzat gora-behera handirik gabe? Nire kasuan behintzat, hogeita hamar urteko lana kostatu izan zait irakurleak Anjel Lertxundiren estiloaren moduan identifikatzen duen hori eraikitzea. Nik erdaraz ez dut halako lanik egin, inondik inora: oso anekdotikoak dira erdaraz idatzi izan ditudan lanak. Orduan, nik ez dut estilo hori lortu gazteleraz, eta nago honez gero ez dudala inoiz lortuko, gogotik saiatuko banintz ere, hemendik aurrera erdaraz bakarrik idaztera mugatuko banintz ere. Berandu da... Beraz, nire bizitza osoa eman baldin badut estilo jakin hori lantzen hizkuntza jakin batean, zertan hasi behar dut neure libururen bat itzultzen, aurrez baldin badakit guztiz neutralizatuta geldituko zaidala nik nahi nukeen estilo hori? ${ }^{8}$ (Egia 1999: 120).

7 «Hay un cuento mío recogido en algunas antologías y que yo mismo traduje al castellano. Se llama Lur hotz hau ez da Santo Domingo [Esta fría tierra no es Santo Domingo]. Cuando lo traduje, al principio no me di cuenta, pero después de concluir el proceso me percaté de un tremendo problema que yo había tenido con el texto. Tengo que confesar algo: el texto publicado en vasco y el que está en castellano son diferentes. El que está en castellano diría que tiene un plus. De algún modo, traicioné el texto original haciendo una especie de working progress, unas trampitas, esquivando los puntos débiles que hay en el texto original, orientándolos de otro modo, etc. Tenía todo el derecho, era mío, y el texto nuevo que estaba creando también era mío, pero, claro, aparecía como traducción y no como adaptación o versión. Así que, traduje aquel cuento, luego lo publiqué, y cuando de ahí a un tiempo contrasté los dos textos, tomé la decisión de que no podía autotraducirme». (La traducción es nuestra).

8 «¿Por qué digo entonces que no puedo autotraducirme si también escribo en castellano, al menos sin excesivos contratiempos? Por lo que a mí respecta, me ha costado treinta años construir ese estilo que el lector identifica como de Anjel Lertxundi. En castellano no he realizado tal tarea, en absoluto: son anecdóticas las obras que he escrito en esa lengua. Así pues, no he logrado ese estilo en castellano, y tengo la impresión de que ya no lo voy a lograr nunca, aunque lo intentara con empeño, aunque a partir de ahora me limitara a escribir en castellano. Es tarde... Así que, si me he pasado toda la vida labrando ese estilo concreto en un idioma concreto, ¿para qué voy a empezar a traducir algún libro mío, si sé de antemano que ese estilo que yo quisiera me va a quedar totalmente neutralizado?». (La traducción es nuestra). 
Ez nintzateke gauza izango nire itzulpen bat egiteko. Liburua berriz idatziko nuke, eta ez dut nahi, planteamendua ez baita hori. Horretarako, zuzenean gaztelaniaz idatziko nuke. Gaztelaniara itzultzen hasita, berria egin beharko nuke, birsortu egin beharko nuke, bertsio bat edo. Zergatik?, bi hizkuntzen egoera oso desberdina delako eta erdaraz idazterakoan kontuan hartu behar duzulako derrigor zer giro dagoen, zer atera den aurreko astean, zer idazten duen jendeak. Euskaraz zentzua duten gauza batzuek gaztelaniaz beharbada ez lukete horrenbesteko zentzurik edukiko. Batetik hori, eta bestetik, norberaren lana itzultzea pisua dela oso; nahiko buelta eman dizkiozu idazterakoan eta berriro horretara jartzea izan daiteke gauzarik eta nazkagarriena. ${ }^{9}$ (Montorio 2007: 71)

Sea como fuere, a juicio de Anjel Lertxundi, todos los escritores del mundo, incluso los monolingües, son al mismo tiempo creadores y traductores, porque cuando escriben están, en realidad, traduciendo sus lecturas previas.

Esango nuke idazle elebakarra ere itzultzaile dela: irakurri dituen beste idazleen itzultzaile edo egokitzaile gertatzen da: lehendik irakurriak dituen erregistro batzuk ari da jasotzen, edo haiek aldatzen, edo haiek erabat ipurdiz gora jartzen. Funtsean, itzultzaileak egiten duen bezalaxe egiten du idazleak ere: aurretik badagoen zerbait hartu eta moldatzen du. Zer esanik ez, egoera hori askoz ere nabarmenagoa da euskal idazlearentzat, mundu zabaleko literatur erreferentzia gehienak erdararen batean irakurriak dituenean, ezinbestean ari da erreferentzia horiek itzultzen, nolabait esateko. Gaur egun egoera hori asko ari da aldatzen, itzultzaileen lan izugarriari esker literatura unibertsaleko erreferentzia gero eta gehiago baitugu euskaraz, baina orain dela 20 urte ez zegoen ia deus ere. ${ }^{10}$ (Egia 1999: 123)

Un caso interesante de autotraducción es el de Bernardo Atxaga con su obra Sara izeneko gizona (vid. López Gaseni 2001). Y es interesante porque se trata de una autotraducción de ida y vuelta, articulada del siguiente modo: 1) el autor escribe una radio-novela en vasco; 2) posteriormente, durante un verano, publica por entregas, en los periódicos El Correo y El Diario Vasco, una novela en español titulada $U n$

9 «No sería capaz de autotraducirme. Reescribiría el libro, y no quiero, porque ese no es el planteamiento. Para eso, lo escribiría directamente en castellano. Una vez hubiera empezado a traducirlo tendría que rehacerlo, tendría que recrear, hacer una versión o algo así. ¿Por qué? Porque la situación de ambas lenguas es muy distinta y porque al escribir en castellano has de tener en cuenta necesariamente qué ambiente hay, qué ha salido la semana anterior, qué escribe la gente. Unas cosas que tienen sentido en vasco quizás no lo tendrían tanto en castellano. Por un lado, eso, y por otro, autotraducirse es una pesada carga: al escribir el libro, le has dado bastantes vueltas, y ponerte ahora a traducirlo puede resultar la cosa más asquerosa del mundo». (La traducción es nuestra).

10 «Diría que incluso el escritor monolingüe es traductor: traductor o adaptador de los demás escritores a los que ha leído. Recoge unos registros que ha leído previamente y los modifica o los vuelve totalmente del revés. En el fondo, el escritor hace lo mismo que el traductor: coge algo previo y lo reelabora. Ni que decir tiene que esa situación es aún más evidente para el escritor éuscaro: dado que la mayoría de las referencias literarias universales las ha leído en una lengua que no es el vascuence, necesariamente las está, por decirlo de algún modo, traduciendo. Hoy en día, esa situación está cambiando mucho, pues gracias al enorme trabajo de los traductores tenemos en vasco cada vez más referencias de la literatura universal, pero hace veinte años no había casi nada». (La traducción es nuestra). 
espía llamado Sara (1996), basada en dicha radio-novela; 3) finalmente, publica la traducción al vascuence (Sara izeneko gizona, 1996) de la novela en español.

Salbuespen oso urriak salbuespen, euskarazko testuari ez zaio nabaritzen itzulpena dela baina, hori bai, benetako Atxagazalea denak faltan botako ditu hasierako liburuetan egile honek hain bereak izan eta sarritan erabiltzen zituen hizkuntza edo hitz jokoak. Dena dela, egilea horren jakitun da. Bere esanetan, ordea, horrela testua ondo lotuta gelditzen da eta zehaztasun aldetik aberatsagoa izan daiteke. ${ }^{11}$ (Aldalur 1997)

Esta tentación de reescribir, de reescribir hasta el infinito, es mencionada también por Harkaitz Cano (Lasarte, Guipúzcoa, 1975): confiesa que, si tuviera que traducir una obra suya al español, se trataría más de una versión que de una traducción, y que, si se reeditase después el original en vascuence, introduciría nuevas modificaciones (Montorio 2007).

Según el parámetro que ahora nos ocupa, podemos clasificar a los escritores vascos en tres tipos:

1) los que se autotraducen al español siempre o casi siempre. Entre otros:

- Lauaxeta (Lauquíniz, Vizcaya, 1905-Vitoria 1937): Bide barrijak (1931, P), obra titulada en español Nuevos caminos; Arrats beran (1935, P), traducida como Al atardecer. En ambos poemarios, junto al texto vasco aparece la traducción española.

- Gabriel Aresti: Harri eta herri (1964, P) [Piedra y pueblo]; Euskal harria (1967, P) [La piedra vasca]; Harrizko herri hau (1970, P) [Este pueblo de piedra]. No obstante, también le tradujeron Eduardo Gil Bera, Jon Juaristi y Javier Atienza.

- Otros autores: Joan Mari Irigoien (Alza, Guipúzcoa, 1948), Unai Elorriaga (Bilbao, 1973), Juan Kruz Igerabide (Aduna, Guipúzcoa, 1956, uno de los de mayor producción traducida, sobre todo en literatura infantil), Mariasun Landa (Rentería, Guipúzcoa, 1949, literatura infantil) ${ }^{12}$, Miren Agur Meabe (Lequeitio, Vizcaya, 1962), Iban Zaldua, Felipe Juaristi (Azcoitia, Guipúzcoa, 1957); Jasone Osoro (Elgóibar, Guipúzcoa, 1971); Karlos Linazasoro (Tolosa, Guipúzcoa, 1962); Itxaro Borda (Bayona, País Vasco Francés,

11 «Salvo raras excepciones, al texto en vasco no se le nota que es una traducción, pero eso sí, el verdadero fan de Atxaga echará en falta los juegos lingüísticos y de palabras que en sus primeros libros este autor empleaba con frecuencia. De todas formas, Atxaga es consciente de ello. Sin embargo, afirma que, de este modo, el texto queda bien fijado y puede resultar más rico en exactitud» (la traducción es nuestra). J. M. López Gaseni (2010) no coincide con Bernardo Atxaga, pues cree que «a la luz de los resultados, podemos decir que la complejidad del texto en castellano hace que el texto en euskera parezca forzado», y remite a ejemplos en los que «la sintaxis vasca quiere imitar la complejidad de la castellana más allá de sus límites habituales, con lo que el lector parece quedarse sin aliento».

12 Respecto a esta autora, J. M. López Gaseni (2010) recoge un interesante caso de autocensura en la autotraducción Mi mano en la tuya (1998). La obra original es Nire eskua zurean (1995). 
1959), que se autotraduce al francés; Ixiar Rozas (Lasarte-Oria, Guipúzcoa, 1972); Aitor Arana (Legazpia, Guipúzcoa, 1963); Aingeru Epaltza (Pamplona, 1960); Karlos Santisteban (Carranza, Vizcaya, 1960).

Bernardo Atxaga se autotraduce con frecuencia: Etiopía (1978, P) Poemas \& híbridos (1990, P, N); Aventuras de Nikolasa (1980, N); Nikolasa, aventuras y locuras $(1989, \mathrm{~N})$; Ramuntxo detective $(1980, \mathrm{~N})$; Nueva Etiopia: conversaciones, poemas y locuras (1996); Obabakoak (1989, N); La gente de mi pueblo (2005, N); Esos cielos (1996, N); Lista de locos y otros alfabetos (1998); Shola y los jabalies $(1997, \mathrm{~N})$; Shola y los leones (1995, N); Dos hermanos (1995, N).

2) los que se autotraducen a veces: Ramon Saizarbitoria (San Sebastián, 1944), en La tradición de Kandinsky $(2003, \mathrm{~N})^{13}$; Arantxa Urretabizkaia, en ¿Por qué, Panpox? (1986, N); Koldo Izagirre (Pasajes, Guipúzcoa, 1953), en Nuevas prisiones del viejo Aguirre (2002, N), Patxi Zubizarreta (Ordicia, Guipúzcoa, 1964), en El bollo de los viernes (1998, N), Paloma, llegaste por el aire (1998, N), Soy el mostooo (1997, N), Que llueva, que llueva (1994, N), etc., todos ellos de literatura infantil; Harkaitz Cano ${ }^{14}$; Txillardegi (San Sebastián, 1929-2012), en Allende el viento (1984, N); Kirmen Uribe (Ondárroa, Vizcaya, 1970), en No soy rubia (2004, N); a Jon Arretxe (Basauri, Vizcaya, 1963) casi siempre le traducen, salvo raras excepciones (Hacia la gran muralla, 2001, N) ${ }^{15}$.

3) los que nunca se autotraducen. Entre otros, Edorta Jiménez (Mundaca, Vizcaya, 1953), traducido por Bego Montorio, José Luis Padrón y Mikel Iriarte; Joseba Sarrionandia (vid. Jaka 2013), traducido por Javier Rodríguez Hidalgo, Bego Montorio y Fermin Arkotxa; Joxe Azurmendi (Cegama, Guipúzcoa, 1941), traducido por Edorta Agirre y Xabier Makazaga; Jon Alonso, traducido por Bego Montorio y Ángela Gezuraga. No obstante, habría que averiguar si en estos casos, aunque el autor no figure como traductor o cotraductor, ha existido un mayor o menor intercambio de opiniones entre autor y traductor. En las traducciones al español nos consta que así suele ser.

13 Por lo demás, a Ramon Saizarbitoria le han traducido Pilar Muñoa, Bego Montorio y Jon Juaristi. Como traductor en su novela Gorde nazazu lurpean (2000) [Guárdame bajo tierra, 2002] figura F. Eguía Careaga. No se trata, en contra de lo que pueda pensarse, de una persona, sino de la Fundación Eguía Careaga, de la cual depende el Centro de Documentación y Estudios SIIS, cuyo director llegó a ser el propio Saizarbitoria.

${ }_{14}$ Su novela Twist fue traducida por Gerardo Markuleta en 2013. Si Harkaitz Cano no fue capaz de traducir su propia novela es porque, según su propia confesión, «no quería volver a entrar en esta dura historia» (Aranguren 2013: 16). En otras declaraciones añadió el cansancio y motivos económicos (la subvención de un organismo público): «Sí me la planteé (la autotraducción), pero sí es verdad que acabé bastante cansado con la escritura del original, veía las páginas que tenía, veía que eran muchas. También es verdad que el Instituto Vasco Etxepare ayudaba a la traducción. Por tanto, no tenía que pedir un favor a nadie, sino que era un trabajo remunerado. Esto también ayudó a que Gerardo Markuleta se animase a hacer la traducción» (Radio Euskadi 2013).

15 A Jon Arretxe le han traducido José Luis Padrón, Iñaki Segurola y Cristina Fernández, Ander Izagirre e Iñaki Mendizabal. 
A caballo entre la traducción y la autotraducción encontramos al tándem formado por el autor y otra persona con la que normalmente mantiene algún tipo de relación más allá de lo estrictamente profesional. Se trata también aquí de casos de traducción del vasco al español. Esta modalidad representa un porcentaje exiguo respecto del total de libros traducidos al español. Veamos algunos ejemplos:

- Bernardo Atxaga y Asun Garikano: El hijo del acordeonista (2004, N); Siete casas en Francia (2009, N); Días de Nevada (2014, N).

- Bernardo Atxaga y Arantza Sabán: El hombre solo (1994, N).

- Miren Agur Meabe y Kepa Murua: El código de la piel (2002, P).

- Kirmen Uribe y Gerardo Markuleta: Mientras tanto dame la mano $(2004, \mathrm{P})^{16}$.

- Pako Aristi (Urrestilla, Guipúzcoa, 1963) y Fermin Etxegoien: Los informes informales $(1997, \mathrm{~N})$.

- Arantxa Urretabizkaia y Maite González: Saturno (1989, N).

- Joan Mari Irigoien y Mikel Lasa: Babilonia (1998, N).

- Joan Mari Irigoien y Edorta Agirre: La tierra y el viento (1997, N).

- Patxi Iturregi (Llodio, Álava, 1952) e Idoia Santamaría: Con el viento en contra $(2000, \mathrm{~N})$.

- Harkaitz Cano y Mikel Iturria: Pasaia Blues (2012, N). Iturria comenzó la traducción y la acabaron él y el autor.

El caso más sorprendente es el de la traducción de la novela de Joan Mari Irigoien Consummatum est, ya que fue realizada, en 2001, a cuatro bandas: Antonio Pérez Esclarín, Esther Sastre, Maite Puignau y el propio autor.

En otros casos, no existe «oficialmente» autotraducción: la traducción está a nombre del traductor, pero este acude al autor para negociar innumerables aspectos textuales, tal como hizo Karlos Cid Abasolo cuando tradujo la novela Ero hiria (en español, Ciudad de locos, 2008), de su amigo Javi Cillero (Bilbao, 1961). Asimismo, las traducciones de las novelas de Anjel Lertxundi están firmadas por su editor (y, sin embargo, amigo) Giménez Bech. Anjel Lertxundi explica (Egia 1999: 121) que algo que al traductor le facilita enormemente su trabajo es que sigue prácticamente en tiempo real el proceso de creación. Incluso la discusión entre ellos a veces comienza antes de que Anjel Lertxundi empiece a escribir su obra en vasco. Esa simbiosis impediría a Jorge Giménez Bech, según propia confesión (Egia 1999: 121), traducir a cualquier otro autor.

El tándem ha sido frecuente en otros sistemas literarios: recordemos que Milan Kundera, para sus novelas escritas en checo, permite que la traducción a cualquier lengua se haga, bien a partir del texto original, bien a partir de la traducción francesa $^{17}$, debido a que, por ejemplo, en la traducción al francés de sus novelas Směšné

${ }^{16}$ El propio Gerardo Markuleta tradujo al español la novela de Uribe Mussche, bajo el título Lo que mueve el mundo (2013).

${ }^{17}$ Eso explica, por ejemplo, un error en la segunda convocatoria de 2007 del concurso «Literatura Unibertsala» (Literatura Universal) del Gobierno Vasco para la adjudicación de traducciones litera- 
lásky (1968), Valčík na rozloučenou (1972), Život je jinde (1973), Kniha smíchu a zapomnění (1978) y Nesnesitelná lehkost bytí (1984), trabajó codo con codo con el traductor François Kerel, colaboración que dio lugar a Risibles Amours (1986), La Valse aux adieux (1986), La vie est ailleurs (1973), Le Livre du rire et de l'oubli (1985) y L'Insoutenable légèreté de l'être (1987). Debemos tener en cuenta, además, que los libros de Milan Kundera, por razones políticas, no podían ser publicados en Checoslovaquia, por lo que los originales en checo solo veían la luz en la editorial canadiense 68 Publishers, del escritor exiliado Josef Škvorecký.

\section{2. ¿Desde qué lengua se traduce la literatura éuscara?}

La respuesta puede parecer obvia, pero no lo es. En el Catálogo ELI (Euskal Literatura Itzuliaren Katalogoa, es decir, Catálogo de Literatura Vasca Traducida), encontramos un listado de más de mil títulos. El problema es que no siempre se indica el idioma de partida (dado que en muchas ediciones no se aporta ese dato) ${ }^{18}$, por lo que las estadísticas que puedan realizarse a partir del ELI tienen un valor relativo.

En traducciones al catalán y al gallego encontramos tanto casos de traducción directa como de traducción indirecta. Por ejemplo, a Patxi Zubizarreta unas veces se le ha traducido al catalán desde el texto vasco (Arròs i tinta, 2006, N) y otras desde la traducción puente castellana (Una estàtua $i$ dos artistes, 2006, N). En otras ocasiones, el traductor se ha basado en ambos textos, como explica Arantxa Urretabizkaia refiriéndose a una novela suya.

Cuaderno Rojo fue traducido al castellano, al alemán, al inglés, al italiano y hasta al ruso si es que, ciertamente, esos caracteres cirílicos corresponden a mi nombre y apellido, como me aseguran. Todas esas traducciones son tan deudoras de la versión castellana como de la original. Soy capaz de reconocer mi voz en la versión castellana, inglesa e italiana, pero no puedo decir nada al respecto de las otras traducciones. Urretabizkaia (2011)

Utilizar como puente la versión española era algo lógico en el pasado, pues pocos eran capaces de traducir del vascuence a otras lenguas que no fueran el español o el francés. No obstante, había alguna que otra excepción: por ejemplo, cuando en 1981 a Arantxa Urretabizkaia le propusieron que fuera publicada su novela Zergatik Panpox? (1979) en catalán, el editor tenía a alguien dispuesto a traducir directamente desde el vasco. Sin embargo, pidió a la autora que tradujera la novela

rias. En la lista figuraba la novela Nesnesitelná lehkost bytí [La insoportable levedad del ser]. Los organizadores establecieron que el texto de partida fuera la traducción francesa (de hecho, en la lista no aparecía el título original en checo, sino el de dicha traducción), y un participante reclamó para que también se aceptara como texto de partida el original checo, que es el que él iba a utilizar para concursar.

18 Así ocurre, por ejemplo, con la traducción al ruso de Koaderno gorria [Krasnaya tetrad, 2007, N], de Arantxa Urretabizkaia, o la traducción al italiano de SPrako tranbia [Un tram a s.p., 2007, N], de Unai Elorriaga. 
al español para facilitar la labor del traductor. Es decir: autotraducir no fue, en ese caso, una iniciativa personal, y la autotraducción se planteó como puente a una posterior traducción a un tercer idioma. La traducción al catalán, titulada Per què, menut?, fue publicada en 1982. Cuatro años después, la traducción al español (¿Por $q u e ́$, Panpox?). Para Arantxa Urretabizkaia, aquello fue un «una y no más, Santo Tomás»:

Traduciendo esa novela decidí que una cosa era hablar y escribir en un idioma, aún con toda la corrección que mi padre nos exigía, y otra bien distinta traducir. Traducir es un oficio que requiere mucho esfuerzo y preparación y decidí que ya tenía suficientes oficios de los que poder vivir para ponerme a aprender otro. Y desde entonces nunca he traducido mis textos. Sé que hay compañeros que lo hacen, que incluso hacen algo más que estricta traducción al verter sus textos al castellano, pero no es mi caso. (Urretabizkaia 2011)

La situación ha cambiado sustancialmente desde aquellos lejanos años 80 del siglo XX, y ya contamos con profesionales que traducen del vasco al alemán (Petra Elser, Jürgen Wolf, Michael Bauer), al italiano (Roberta Gozzi), o al inglés (Amaia Gabantxo, Elizabeth Macklin, Maddalen Saizarbitoria, Kristin Addis). No hay que olvidar, además, que el Gobierno Vasco lleva años firmando convenios para que se implante el vascuence en los programas de estudios de universidades de todo el mundo, gracias a lo cual se ha ido creando una notable cantera de traductores. Sin embargo, algunos autores no parecen muy dispuestos a seguir ese camino: Bernardo Atxaga, el más internacional de los escritores vascos (o, dicho con otras palabras, el más traducido) es un caso paradigmático de traducciones a otras lenguas vía la versión española -vía una «lengua-sol», como él mismo dice (Atxaga 2009: 129)-. Eso podría entenderse si no existieran traductores que conozcan el vascuence («lengua-asteroide») y la lengua-meta. Pero la cuestión es que, como decíamos, en la actualidad hay traductores que, además de vasco, saben francés, italiano, alemán o catalán, y también en esos casos Bernardo Atxaga prefiere que el traductor parta de la versión española. No obstante, hemos detectado algunas excepciones en las que ha sido traducido directamente desde el vasco:

- Traducción al alemán de Behi euskaldun baten memoriak (1991, N): Memoiren einer baskischen Kuh (1995, Ludger Mees).

- Traducción al catalán de Zeru horiek (1995, N): Aquells cels (1999, Pau Joan Hernández).

- Traducción al catalán de Chuck Aranberri dentista baten etxean (1982, N): Chuck Aranberri a cal dentista (1990, Josep Daurella).

- Traducción al gallego de Sugeak txoriari begiratzen dionean (1984, N): Cando a serpe mira o paxaro (1995, Martin Mendizabal y Xosé Manuel González Barreiro).

Varios pueden ser los motivos que impulsen a algunos autores a preferir que la traducción al español sirva de puente a las traducciones a otros idiomas: 
- hay más traductores desde el español que desde el vasco a cualquier lengua. Hay, por tanto, más donde elegir;

- hay traductores a más lenguas desde el español que desde el vasco;

- existe la opinión de que resulta más fácil traducir a una lengua indoeuropea desde otra lengua indoeuropea que desde una lengua no indoeuropea (por ejemplo, el vasco).

- por lo general, los textos literarios en español presentan una mayor complejidad sintáctica que en vascuence, y por ello, una traducción literal de este a aquel podría tener una recepción poco favorable. Para evitar que eso también ocurra en la traducción a otros idiomas, una solución puede ser recurrir como texto de partida a la traducción al español. Si (como en el caso de Bernardo Atxaga, el cual, como ya vimos anteriormente, apelaba a estos mismos motivos de genealogía lingüística para justificar la autotraducción) la traducción es, al menos parcialmente, obra del propio autor, esta decisión resulta más fácil de tomar.

El hecho de que, por razones histórico-políticas, el vascuence no haya sido una lengua normalizada ha podido contribuir, más que su genealogía, a la brecha abierta respecto a otras lenguas. El léxico es, al igual que la sintaxis, otro de los frentes abiertos. Bernardo Atxaga lo explica del siguiente modo:

Nik honelaxe ikusten dut (marrazkiaz ilustratzen du): hau izango litzateke, multzo handi hau, kultur hizkuntza batetik datorrena, eta hona, euskararen multzo txikira, pasatzerakoan, nola, eman dezagun ez dela izan kultur hizkuntza, behintzat besteen tamainan, eta nolaz ez baitzen hor egon talde askorik hitzegiten -ia esango genuke herri xeheak eta Elizak bakarrik hitzegin dutela-... orduan hau askoz ere txikiagoa da, ezta?, niri hau iruditzen zait dela, ez dakit ba... tuboetan bezala ikusten dut nik. Imajinatu hau dela ubide bat zabala, sekulako ur pila dakarrena, eta bapatean egin beharra daukazu hemen halako-fst!-estualdi bat, eta sartu beharra daukazu dauzkazun bi edo hiru molde horietan. Ez dakit adibidea ona den, baina «dejar» «utzi» da, eta «abandonar» ere «utzi», eta «hacer dejación» ere «utzi», eta dena da «utzi». Horregatik da hain erraza itzulpena beste hizkuntza batetik gurera, horretan sartzen dituzu hor dauden matizazio guztiak, ezta? ${ }^{19}$ (Garzia Garmendia 1990: 17-18)

Así pues, en esta metáfora de los tubos grandes y pequeños podemos encontrar quizás las razones de la decisión del escritor de Asteasu de que la traducción de sus libros al alemán, italiano, francés, etc., partan de la traducción del original vasco al español y no directamente del original. Podría pensarse que tal metáfora entra en

19 «Yo lo veo así (lo ilustra con un dibujo): ese gran conjunto sería lo que viene de una lengua de cultura, y al pasar aquí, al pequeño conjunto del vascuence, supongamos que no ha sido una lengua de cultura, al menos en la medida del resto, y como no lo hablaba mucha gente -casi diríamos que lo han hablado solo el pueblo llano y la Iglesia-... entonces es mucho más pequeño, ¿verdad?, a mí me parece que esto es, no sé... yo me imagino unos tubos. Supón que esto es un cauce muy ancho con muchísimo caudal y que de repente tienes que hacer aquí un estrechamiento y tienes que meterlo en esos dos o tres moldes que tienes. No sé si el ejemplo es bueno, pero «dejar», en vasco, es «utzi», y «abandonar» también es «utzi», $\mathrm{y}$ «hacer dejación» también es «utzi», y todo es «utzi». Por eso es tan fácil traducir al vasco desde otro idioma, en eso introduces todas las matizaciones que hay ahí, ¿verdad?». (La traducción es nuestra). 
contradicción con cierta opinión anterior del mismo autor, vertida en su ensayo Alfabeto sobre la cultura vasca.

[...] o lo que un buen porcentaje de periodistas -franceses, alemanes, estadounidenses- suele preguntar a los escritores en lenguas minoritarias en general y a los escritores vascos en particular: ¿Por qué no escribe usted en una lengua menos limitada? Son, todas ellas, opiniones que niegan la igualdad ontológica de todas las lenguas, y que lo único que demuestran es la gran afición que el ser humano tiene a hablar de cosas que no sabe, y la poca afición que, por contra, tiene a los libros de lingüística. Porque, naturalmente, hace ya bastante tiempo que los lingüistas dejaron zanjada esta cuestión. ¿No fue Jakobson el que escribió que toda experiencia cognoscitiva y su clasificación son atribuibles en cualquier lengua existente? ¿Y no fue Bloomfield quien afirmó que todo lo que puede ser dicho en una lengua dada puede, sin duda alguna, ser dicho en otra? (Atxaga 1995: 60)

Para que ambas opiniones resulten conciliables, cabe interpretar que para Bernardo Atxaga existe una igualdad ontológica de las lenguas desde el punto de vista de los significados, pero no de los significantes.

\section{Dos ejemplos de autotraducción}

Para finalizar, vamos a ofrecer dos ejemplos de autotraducción, extraídos de Kandinskyren tradizioa (2003, N) / La tradición de Kandinsky (2003, edición bilingüe), de Ramon Saizarbitoria, y Soinujolearen semea (2003, N) / El hijo del acordeonista (2004, traducción de Asun Garikano y el propio autor, Bernardo Atxaga). Huelga decir que en muchos casos la traducción es literal, pero aquí nos ocuparemos de otros en los que no lo es.

Kandinskyren tradizioa / La tradición de Kandinsky (Saizarbitoria 2003)

\begin{tabular}{|c|c|c|}
\hline TEXTO EN VASCO & TRADUCCIÓN LITERAL & $\begin{array}{c}\text { TRADUCCIÓN } \\
\text { PUBLICADA }\end{array}$ \\
\hline $\begin{array}{l}\text { Esaten zidan nobela klasikoak } \\
\text { denbora pasako asko baino } \\
\text { errazago irakurtzen direla, hori } \\
\text { baita neure esperientzia: Ana } \\
\text { Karenina, esaterako, amaitzeko } \\
\text { penaz irakurri bainuen, eta beste } \\
\text { asko. }\end{array}$ & $\begin{array}{l}\text { Me decía que las novelas } \\
\text { clásicas se leen más fácilmente } \\
\text { que muchas que son para pasar } \\
\text { el rato, porque esa es mi propia } \\
\text { experiencia; porque, por ejemplo, } \\
\text { leí Ana Karenina con pena de } \\
\text { que se acabase, y otras muchas. }\end{array}$ & $\begin{array}{l}\text { Me dice que algunos clásicos } \\
\text { son más entretenidos que } \\
\text { muchos libros de evasión, } \\
\text { porque esa es mi propia } \\
\text { experiencia; Ana Karenina, por } \\
\text { ejemplo, a medida que la iba } \\
\text { leyendo, me daba pena que se } \\
\text { acabase, y como esa otras. }\end{array}$ \\
\hline $\begin{array}{l}\text { Harridura erakutsi bazuen ere, } \\
\text { agerikoa zen jakitetik mintzo } \\
\text { nintzela iruditzen zitzaiola. }\end{array}$ & $\begin{array}{l}\text { Aunque mostró asombro, era } \\
\text { evidente que le parecía que yo } \\
\text { hablaba desde el conocimiento. }\end{array}$ & $\begin{array}{l}\text { Se sorprendió, pero era evidente } \\
\text { que estaba convencida de que le } \\
\text { hablaba con conocimiento de } \\
\text { causa. }\end{array}$ \\
\hline
\end{tabular}

Continúa... 


\begin{tabular}{|c|c|c|}
\hline TEXTO EN VASCO & TRADUCCIÓN LITERAL & $\begin{array}{c}\text { TRADUCCIÓN } \\
\text { PUBLICADA }\end{array}$ \\
\hline $\begin{array}{l}\text { Hotel aurreko zelaiunea kamioiz } \\
\text { beteta zegoen eta ez zen eztandaren } \\
\text { aztarrenik nabari. Ez polizia } \\
\text { autoenik ezta anbulantzienik ere. } \\
\text { Ez dakit zergatik, egonak ginen } \\
\text { gelako leihoa atzeman nahi izan } \\
\text { nuen; duda nuen biren artean. Aitor } \\
\text { hurbildu zitzaidanean galdetu egin } \\
\text { nion ea zein uste zuen izan } \\
\text { zitekeela. }\end{array}$ & $\begin{array}{l}\text { La explanada de delante del } \\
\text { hotel estaba llena de camiones y } \\
\text { no se apreciaba ningún indicio } \\
\text { de la explosión. Ni de los } \\
\text { coches-patrulla ni de las } \\
\text { ambulancias. No sé por qué, } \\
\text { traté de identificar la ventana de } \\
\text { la habitación en la que habíamos } \\
\text { estado; dudaba entre dos. } \\
\text { Cuando Aitor se me acercó, le } \\
\text { pregunté cuál creía que podía } \\
\text { ser. }\end{array}$ & $\begin{array}{l}\text { La explanada de delante del } \\
\text { hotel estaba llena de camiones y } \\
\text { no se apreciaba ningún indicio } \\
\text { de que se hubiera producido una } \\
\text { explosión minutos antes. A } \\
\text { saber por qué, traté de } \\
\text { identificar la ventana de la } \\
\text { habitación en la que habíamos } \\
\text { estado; dudaba entre dos. } \\
\text { Cuando se me acercó, le } \\
\text { pregunté a ver cuál creía que } \\
\text { podía ser. }\end{array}$ \\
\hline $\begin{array}{l}\text {-Dei iezadazu sin falta -esan nion } \\
\text { inongo erreparorik gabe, eta kalera } \\
\text { atera nintzenean gorputza arina } \\
\text { sentitu nuen, betetzen ninduen } \\
\text { zorionak airean eutsiko balit } \\
\text { bezala, eta iruditu zitzaidan bistaz } \\
\text { hartzen nuen guztiak, hodeiak, } \\
\text { teilatuak, adaburuak, sortzeko } \\
\text { nengoen margolan paregabe bat } \\
\text { osatzen zuela. }\end{array}$ & $\begin{array}{l}\text {-Llámame sin falta -le dije sin } \\
\text { ningún reparo, y cuando salí a la } \\
\text { calle sentí el cuerpo ligero, } \\
\text { como si la felicidad que me } \\
\text { llenaba me sujetara en el aire, y } \\
\text { me pareció que todo cuanto } \\
\text { abarcaba con la vista, las nubes, } \\
\text { los tejados, las copas de los } \\
\text { árboles, componía un cuadro sin } \\
\text { par que estaba por pintar. }\end{array}$ & $\begin{array}{l}\text {-Llámame sin falta -añadí, sin } \\
\text { ningún rubor y, cuando salí a la } \\
\text { calle, sentí el cuerpo ligero, } \\
\text { como si la felicidad que me } \\
\text { embargaba me hiciera flotar, y } \\
\text { me pareció que todo cuanto } \\
\text { abarcaba mi vista, las nubes, los } \\
\text { tejados, las copas de los árboles, } \\
\text { componían un cuadro precioso } \\
\text { que estaba por pintar. }\end{array}$ \\
\hline
\end{tabular}

Soinujolearen semea / El hijo del acordeonista (Atxaga, 2003, 2004)

\begin{tabular}{|c|c|c|}
\hline TEXTO EN VASCO & TRADUCCIÓN LITERAL & $\begin{array}{l}\text { TRADUCCIÓN } \\
\text { PUBLICADA }\end{array}$ \\
\hline $\begin{array}{l}\text { «Zer eskainiko diguzu?», } \\
\text { galdetu zion maistrak. «Padam } \\
\text { Padam», esan nuen nik aurrea } \\
\text { hartuz. Banekien ondo jotzen } \\
\text { zuela pieza hura. Nahitaezko } \\
\text { gaia zen urte hartako Akordeoi } \\
\text { Lehiaketan, eta bere aitak behin } \\
\text { eta berriro joarazten zion. } \\
\text { Davidek gogaitu aurpegia jarri } \\
\text { nahi izan zuen oraingoan, baina } \\
\text { lortu gabe. }\end{array}$ & $\begin{array}{l}\text { «¿Qué nos vas a ofrecer?», le } \\
\text { preguntó la maestra. «Padam } \\
\text { Padam», dije yo tomando la } \\
\text { delantera. Yo sabía que él tocaba } \\
\text { bien aquella pieza. Era tema } \\
\text { obligatorio en el concurso de } \\
\text { acordeón de aquel año, y su } \\
\text { padre le obligaba a tocarla una y } \\
\text { otra vez. David quiso poner en } \\
\text { esa ocasión cara de aburrimiento, } \\
\text { pero sin conseguirlo. }\end{array}$ & $\begin{array}{l}\text { «¿Qué vas a interpretar?», } \\
\text { preguntó la maestra. «Padam } \\
\text { Padam», dije yo, anticipándome a } \\
\text { su respuesta. Era la canción que } \\
\text { mi compañero mejor conocía, la } \\
\text { que más veces había ensayado por } \\
\text { ser un tema de ejecución obligada } \\
\text { en el curso provincial de } \\
\text { acordeonistas. David no pudo } \\
\text { contener la sonrisa. }\end{array}$ \\
\hline
\end{tabular}

Continúa... 


\begin{tabular}{|c|c|c|}
\hline TEXTO EN VASCO & TRADUCCIÓN LITERAL & $\begin{array}{l}\text { TRADUCCIÓN } \\
\text { PUBLICADA }\end{array}$ \\
\hline $\begin{array}{l}\text { Luze gabe, ahaztu egin nuen } \\
\text { berriro, eta ezerez horretan } \\
\text { geratu zen harik eta, liburua } \\
\text { idazteko ahaleginetan ari } \\
\text { nintzela, burura itzuli zitzaidan } \\
\text { arte. Aukera bat zela pentsatu } \\
\text { nuen. Nik ere banuela ondo } \\
\text { gogoratzeko premia, behar nuela } \\
\text { gida bat zirriborroetako hitzak } \\
\text { zein bere lerro egokian jartzeko. }\end{array}$ & $\begin{array}{l}\text { Sin dilación, lo volví a olvidar, y } \\
\text { se quedó en esa nada hasta que, } \\
\text { cuando estaba esforzándome en } \\
\text { escribir el libro, me volvió a la } \\
\text { cabeza. Pensé que era una } \\
\text { posibilidad. Que yo también } \\
\text { tenía la necesidad de recordar, } \\
\text { que necesitaba una guía para } \\
\text { poner las palabras de los } \\
\text { borradores cada una en su línea } \\
\text { adecuada. }\end{array}$ & $\begin{array}{l}\text { [...] y no volví a tenerlo presente } \\
\text { hasta que, ya en América, empecé } \\
\text { a escribir mi libro y decidí aplicar } \\
\text { aquel modo de recordar: iría de un } \\
\text { tema a otro igual que los dedos } \\
\text { del agente de seguros habían ido } \\
\text { del trozo de carbón a la astilla } \\
\text { abrasada o a las mariposas. } \\
\text { «Guarda el cordón. Algún día te } \\
\text { será útil», me dijo aquel hombre. } \\
\text { Su profecía iba a cumplirse. }\end{array}$ \\
\hline $\begin{array}{l}\text { Eguerdian Visaliako aireportura } \\
\text { joan naiz Mary Annekin, eta } \\
\text { Joseba jaso dugu. Irtetean, } \\
\text { aparkamendua ordaintzeko } \\
\text { ilaran geundela, adineko andre } \\
\text { bat kexuka hasi da, Chicagotik } \\
\text { zetorrela eta «halako bidaia } \\
\text { luzeek birrindu egiten zutela». } \\
\text { Bere gisara ari zen marmarka, } \\
\text { baina halako batean Josebari eta } \\
\text { bioi erreparatu digu. «Zuek ere } \\
\text { ez duzue bidaia laburra egin, } \\
\text { zuen aurpegia ikusi besterik ez } \\
\text { dago!», jaulki du. }\end{array}$ & $\begin{array}{l}\text { Al mediodía he ido con Mary } \\
\text { Ann al aeropuerto de Visalia y } \\
\text { hemos recogido a Joseba. Al } \\
\text { salir, cuando estábamos en la fila } \\
\text { para pagar el aparcamiento, una } \\
\text { señora de edad ha empezado a } \\
\text { quejarse, que si venía de Chicago } \\
\text { y que si viajes tan largos la } \\
\text { desfondaban. Murmuraba para sí, } \\
\text { pero en una de estas se ha fijado } \\
\text { en Joseba y en mí: «iTampoco } \\
\text { ustedes han hecho un viaje corto, } \\
\text { no hay más que verles la cara!», } \\
\text { ha espetado. }\end{array}$ & $\begin{array}{l}\text { Este mediodía he ido con Mary } \\
\text { Ann al aeropuerto de Visalia para } \\
\text { recoger a Joseba. A la salida, en la } \\
\text { cola para pagar el aparcamiento, } \\
\text { una mujer que al parecer venía de } \\
\text { Chicago ha empezado a quejarse } \\
\text { de la fatiga que le producen los } \\
\text { viajes largos. Se lamentaba en voz } \\
\text { baja, hasta que se ha fijado en } \\
\text { Joseba y en mí y ha dicho: } \\
\text { «Tampoco ustedes tienen muy } \\
\text { buen aspecto. A saber cuánto } \\
\text { tiempo llevan de viaje». }\end{array}$ \\
\hline
\end{tabular}

A simple vista, parece que Ramon Saizarbitoria es más partidario de una traducción pegada al original, en tanto que Asun Garikano y Bernardo Atxaga se permiten un mayor número de licencias que hacen del texto en español más una versión (consecuencia de un proceso de reescritura) que una traducción.

Otro ejemplo en el que nos encontramos más cerca de la versión que de la traducción es Moroak gara behelaino artean? (2010), de Joseba Sarrionandia, ensayo vertido por Javier Rodríguez Hidalgo al español con el nombre de ¿Somos como moros en la niebla? (2012), texto revisado y ampliado por el autor. El libro en vasco tiene 709 páginas, y en español 973. Es decir: Joseba Sarrionandia, como él mismo aclara, decidió incorporar a la traducción una gran cantidad de pasajes ausentes del texto original.

Se amplían algunos temas, se introducen otros. Por ejemplo, al interlocutor vascoparlante no sentí la necesidad de plantearle el tema del valor de la lengua, porque pienso que tiene asumido ese valor. En castellano he introducido una línea de reflexión al hilo de El oro de Caramablú, de Johannes Urzidil. Era un escritor judío de Praga, amigo de Franz Kafka, y escribió un hermoso relato simbolista sobre el norte del País Vasco ambientado cuando al otro lado de la frontera se desarrollaba la Guerra Civil. La lengua, el tesoro de la montaña, es la pizca de oro que brilla en los labios de las personas; cada lengua en particular y el lenguaje como tal. He ampliado tam- 
bién el análisis de los conceptos de Miguel de Unamuno y Pío Baroja en relación a la política. (Okariz 2012)

\section{Final}

Finaliza ya este periplo por el mundo de la traducción y la autotraducción de la literatura vasca. Seguramente, muchas de las ideas aquí vertidas son aplicables a cualquier otra lengua minorizada, cualquier otra «lengua-asteroide». La dependencia respecto de la «lengua-sol» es evidente. Pero, en cualquier caso, el hecho de que la literatura vasca, en las condiciones que sean, se traduzca representa un hito en su historia. 